\title{
Recombinant Anti-WT1 Immunotherapeutic GSK2302024A
}

National Cancer Institute

\section{Source}

National Cancer Institute. Recombinant Anti-WT1 Immunotherapeutic GSK2302024A. NCl Thesaurus. Code C116880.

An immunotherapeutic composed of the Wilms tumor 1 (WT1) and an as of yet undisclosed adjuvant, with potential antineoplastic activity. Upon administration, the immune system may be stimulated to exert a cytotoxic $T$-lymphocyte $(C T L)$ response against WT1-expressing tumor cells. The adjuvant stimulates the immune system's response to WT 1. WT 1, a tumor-associated antigen (TAA) and transcription factor, is overexpressed in a variety of tumor cell types. 